\title{
WEBDEV-A Six Sigma DMAIC based Web Portal Design Framework
}

\author{
Kalaimagal Sivamuni \\ Department of IT \\ BVRIT, \\ Narsapur, AP, India.
}

\author{
Jagan Amgoth \\ Department of CSE \\ BVRIT, \\ Narsapur, AP, India
}

\begin{abstract}
As the internet grows day by day in terms of online users, different kinds of web portals like AOL, MSN and Yahoo are also increasingly being used. Customer Satisfaction is important for the success of web portals. Some of the important factors that determine customer satisfaction of web portals are usability, efficiency and excellent content. Although there are many research papers that discuss different techniques for evaluating the quality of web portals, there is a huge gap in research concerning how to build quality web portals from scratch. Six Sigma is a methodology that has stormed the manufacturing world and is renowned for improving the quality of products and processes and also for designing high quality products and processes. In recent times the IT industry is also successfully trying to adapt Six Sigma methods to create defect free software. This paper proposes a design framework called WEBDEV using the SIX SIGMA DMAIC methodology that can be used to design high quality web portals from scratch.
\end{abstract}

\section{Keywords}

Six Sigma, DMAIC, Web Portal Design, Web Service Quality

\section{INTRODUCTION}

A web portal is a web site that serves as a single window for access to information from different sources across the internet. Research literature is replete with accounts about organizations integrating web technologies into their operations through the use of web portals and websites $[9,10]$.This is because by using web technology ,organizations can reach out to customers and provide them not only with only general information about their products or services but also give them the opportunity for performing interactive business transactions[13].Many case studies have also shown that organizations have started realizing that they need to have quality web portals or else they might end losing a segment of their customers [16].

Therefore the quality of web portals has become a burning topic in recent years which has resulted in a lot of research on how to measure the quality of existing portals and also on how to improve the quality of existing portals. On the contrary, there is a lesser focus on how to build quality portals from scratch [11].It will be better if companies focus on how to build quality portals from scratch the first time itself as it will save them time, cost and money instead of building the portal, conducting a quality evaluation and then make corrections which will cost them more effort. Although, Timothy Kraus [12] has discussed ways to design quality web portals there is no structured framework or process laid down that will help developers build quality sites.
This paper proposes a design framework that will help developers to build quality web portals. After studying several quality methodologies we decided to follow the Six Sigma methodology to create the framework because Six Sigma has had a huge success in the manufacturing sector and has been successfully applied in the software industry also [8]. The entire fulcrum of Six Sigma is to decrease defects and increase quality and customer satisfaction by constant monitoring. Six sigma has two methodologies DMAIC(Define ,Measure ,Analyze, Improve and Control) that is used to improve products and processes and DFSS (Design For Six Sigma) that can be used for creating new products or processes. The first question that arises is which of these methodologies we should adopt to create web portals. The solution depends on the kind of web portal we are going to develop as there are two situations:

Case 1: There are similar examples of the proposed web portal already existing. For example if bank XYZ wants to create a online portal there are a lot of online banking portals already available.

Case 2: The proposed web portal is based on a totally new idea .For example, a food management portal which aims to transfer excess food to the needy.

The DMAIC methodology can be used to develop Case 1 type of portals (where we need to improve upon existing portals )and the DFSS methodology can be used to create Case 2 type of portals that have to be designed from scratch. Since each methodology has different steps and tasks two kinds of web development frameworks will have to be designed that supports each methodology respectively.

This paper proposes a design framework based on the DMAIC methodology that can be used to develop quality web portals. Section 2 of this paper described the steps in the framework and Section 3 presents the future work that has to be done.

We ask that authors follow some simple guidelines. In essence, we ask you to make your paper look exactly like this document. The easiest way to do this is simply to download the template, and replace the content with your own material.

\section{THE WEBDEV FRAMEWORK}

The WEBDEV design framework is a Six Sigma based web portal development model that can be used to design and create quality web portals. The WEBDEV design framework has five phases. Each phase has a list of activities and lists of documents are generated in each phase. We shall now describe the activities and outputs of each stage in the WEBDEV framework. The Design Framework has been illustrated in Figure 1 below: 


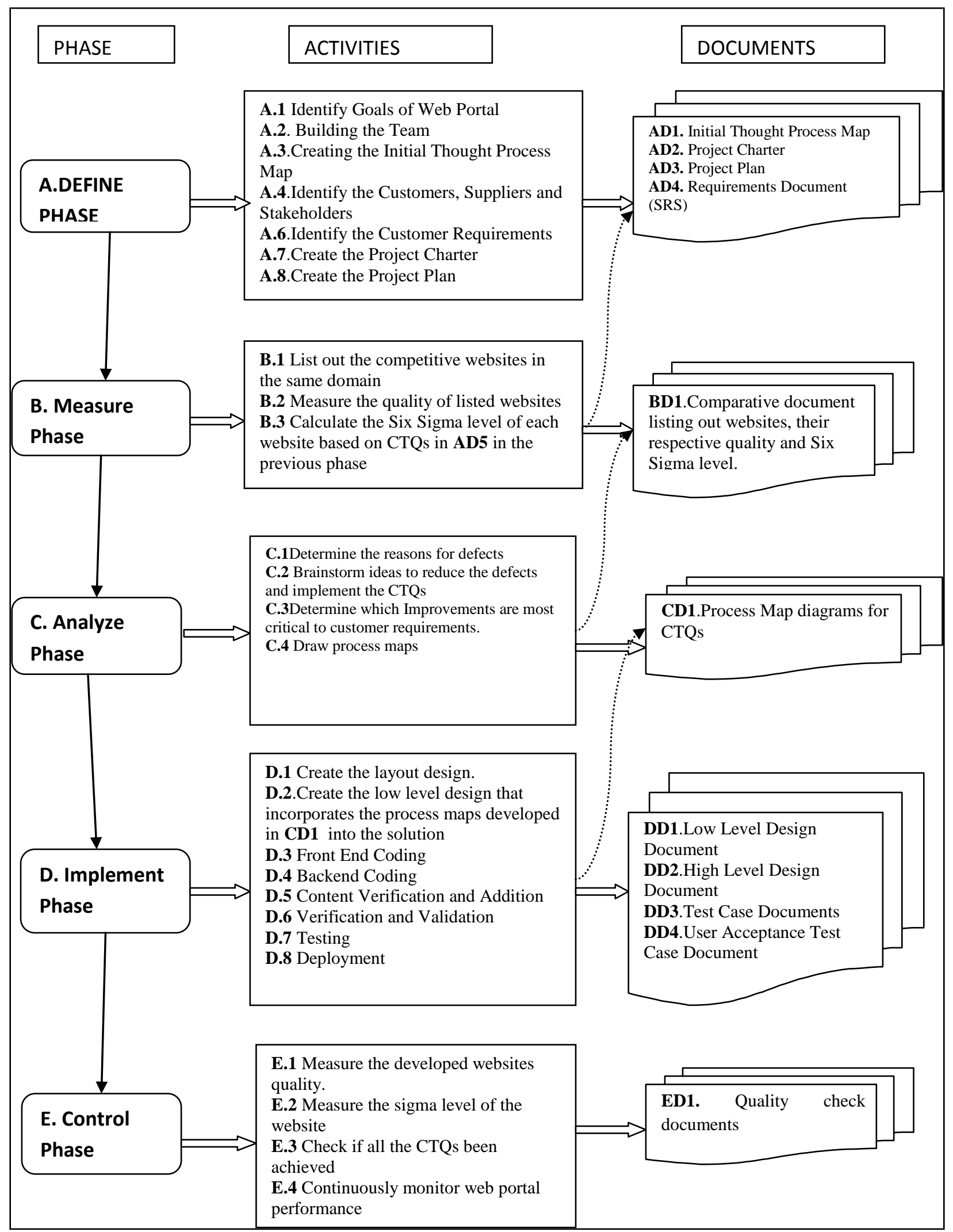

Figure 1: The WEBDEV DESIGN FRAMEWORK 


\section{A. Define Phase}

The purpose of the define phase is to create an understanding between the customer and the project team about the project objectives, customer requirements, plan of execution and project outputs. The Define phase has the following activities as can be seen in Figure 1. Let us now discuss what the tasks each activity encompasses are:

\section{A.1) Activity 1: Identify the goals of the web portal}

Many web portals today are built with no tangible goals in mind which is the main reason for many of them not succeeding. Some of the reasons for unsuccessful web sites are :

$>$ The goals are too vague to implement (E.g.: I want my site to be the best)

$>\quad$ The goal is unrealistic (E.g.: I want my e commerce stall to sell $1000 \mathrm{t}$ shirts in a month).

$>$ The goal is a reaction to a competitor ( E.g. : I want my site to be better than others.)

According to Christine.B.Tayntor [3], the goal should be SMART where SMART is an acronym for (Specific, Measurable, Attainable, Relevant and Time bound). The sub goals are:

$>$ Specific: The goals should be specific and succinct and written in a few but meaningful words.

$>$ Measurable: Goals should be measurable (for e.g., the portal should be able to service 1000 customers a day.)

> Attainable: The goals listed should be within the scope of the proposed web portal and should be feasible.

Delevant: Goals should be relevant to the purpose for which the web portal is being developed.

$>$ Time bound: Goals should be set in such a way that they can be achieved within a time frame.

\section{A.2) Activity 2: Building a Team}

The next important step is to form a team. It is essential to identify correct members for the team. An ideal web portal development team will comprise the following members:

A) Project Manager: The project manager should preferably be someone who has ten years of experience in various stages of website development like designing, content management etc.

B) Web Developers: The web developer should preferably be a person who specializes in the development of World Wide Web applications or distributed network applications that run over http from a web server or a web browser. Modern web applications consist of two or more tiers. The team will be balanced if we have two or more developers specializing in different technologies. For example one developer can be well versed in client technologies like HTML, JavaScript, CSS , while another developer can be focused on server side technologies like PERL,Ruby,.NET MVC and another developer can be focused on server side interactions that involve web servers.

C) Web Designers: Web designers are the people who specialize on how the web site looks and how the customer interacts with it. They are responsible for using the principles of design to make the site look and feel great. They should also be experts at usability so that customers find it easy to navigate around the web site.

(Note: although the terms web development and web design are used interchangeably, there is a clear difference between web site development and web site design. Web design is the process of designing a web site and planning the layout which includes the graphical elements. Web Development is the programming required to construct the "back end " of the web portal.)

D) Content Manager: Every website requires different type of content depending on the audience it caters to. The team should have a copywriter who is responsible for creating the content and making it relevant to the audience and easy to access. The content manager will have the following responsibilities:

a. Creating and editing content

b. responsibility for releasing the content

c .responsibility for tuning the content including translation and delivery.

E) Database Administrators: If the web site uses a database then it is important to have a database administrator .The database administrator will handle the installation, configuration, upgrade and maintenance of the database.

G) Marketing Personnel: Customer feedback and requirements form the main backbone of any Six Sigma process. It is advised to have a separate team for marketing who is responsible for conducting surveys and getting customer feedback.

\section{A.3) Activity 3 :Create the Initial Thought Process Map (TMAP)}

Once a team has been established, then a first meeting should be conducted when the initial thought process map (TMAP) for the web portal project should be drawn .A TMAP is the first Six Sigma tool that should be used in any DFSS project. It is a visual representation of the entire team's thoughts, ideas and questions relative to accomplishing the project goals.

The questions which should be addressed in a TMAP for a Six Sigma web portal design are the following:

$>$ What is the purpose of the website? Is it going to sell a product, promote a service or provide information?

$>$ Identify the target audience of the web site .Try to picturise the ideal person who would visit the website.

$>$ Redefine the goal stated in task 1 and try to divide it into sub goals. Perform a check on whether the goals can be accomplished.

$>$ Identify and list out existing web portals that offer the same service.

$>$ Decide what kind of content will be on the web site in a broad context.

$>$ Identify the name of the website.

$>$ Define the scope of the web portal.

$>$ Identify the sources for data

$>$ Identify the software and hardware requirements for the web site

$>$ Identify how the success of the website will be measured.

$>$ Discuss the differentiators between the portal and already existing web portals broadly.

A.4) Activity 4: Identify the customers, suppliers and stake holders:

Customers are the audience who will use the web sites. The stakeholders of the web site will be the content creators, bloggers, registered users, suppliers (if it is a commercial site selling products), Site Members, Topical Experts, Mainstream Media. It is the responsibility of the marketing team to identify and distinguish between the customers, suppliers and stake holders. 


\section{A.5) Identify the customer requirements:}

This can be done by first selecting a the audience and then conducting surveys, distributing questionnaires and personal interviews. Once the customer requirements are listed, the most essential or Critical to Quality requirements (CTQs) are identified and listed out.

\section{A.6) Create the Project Charter:}

The next task is to design the project charter for the web portal. A project charter will articulate the problems that the team is going to work on and discusses the projects scope , goal and objectives in a very clear terms. We have designed a project charter that can be used exclusively for Six Sigma DMAIC process for designing web sites. The project charter is illustrated in Table 1 below:

Table 1: WEBDEV Project Charter

\begin{tabular}{|l|l|}
\hline \multicolumn{2}{|c|}{ Project Charter } \\
\hline \multicolumn{2}{|c|}{ A. General Information } \\
Project & \\
\hline $\begin{array}{l}\text { Name } \\
\text { Spoject }\end{array}$ & \\
\hline $\begin{array}{l}\text { Project } \\
\text { Manager }\end{array}$ & \\
\hline $\begin{array}{l}\text { E mail \& } \\
\text { Phone No }\end{array}$ & \\
\hline Start Date & \\
\hline $\begin{array}{l}\text { Completion } \\
\text { Date }\end{array}$ & \\
\hline $\begin{array}{l}\text { Estimated } \\
\text { Costs }\end{array}$ & \\
\hline Green Belt & \\
\hline Black Belt & \\
\hline Issues ,Goals and Objectives \\
\hline Objective \\
\hline Scope
\end{tabular}

\begin{tabular}{|l|l|}
\hline \multicolumn{2}{|c|}{ D. Project Resources } \\
\hline $\begin{array}{l}\text { Team } \\
\text { Members }\end{array}$ & \\
\hline $\begin{array}{l}\text { Support } \\
\text { Resources }\end{array}$ & \\
\hline $\begin{array}{l}\text { Special } \\
\text { Needs }\end{array}$ & \\
\hline \multicolumn{1}{|c|}{ E. Project Owners, Stake Holders and } \\
Customers \\
\hline Owners & \\
\hline Stakeholders & \\
\hline $\begin{array}{l}\text { Final } \\
\text { Customers }\end{array}$ \\
\hline \multicolumn{2}{|c|}{ F. Project Risks .Constraints and Assumptions } \\
\hline
\end{tabular}

\section{A.7) Activity 7: Create the Project Plan}

The project charter is then expanded into a project plan. A well designed project plan plays a key role in the success of any Six Sigma process. As part of the process, we have designed a generic project plan that can be used for a designing any web portal. It is illustrated in Table 2 below:

Table 2: WEBDEV Project Charter

\begin{tabular}{|l|l|l|l|l|}
\hline S.No & Task Priority & $\begin{array}{l}\text { Start } \\
\text { date }\end{array}$ & $\begin{array}{l}\text { End } \\
\text { date }\end{array}$ \\
\hline A.1 & A.DEFINE PHASE & & & \\
\hline A.2 & Building the team. & & & \\
\hline A.3 & $\begin{array}{l}\text { Creating the Initial } \\
\text { Thought Process Map. }\end{array}$ & & & \\
\hline A.4 & $\begin{array}{l}\text { Identify the customers, } \\
\text { suppliers and stakeholders. }\end{array}$ & & & \\
\hline A.5 & $\begin{array}{l}\text { Identify the Customer } \\
\text { Requirements. }\end{array}$ & & & \\
\hline A.6 & $\begin{array}{l}\text { Identify Critical to Quality } \\
\text { Requirements(CTQs). }\end{array}$ & & & \\
\hline A.7 & Create the Project Charter. & & & \\
\hline A.8 & Create the Project Plan. & & & \\
\hline websites in the same & B.MEASURE PHASE & & & \\
\hline
\end{tabular}




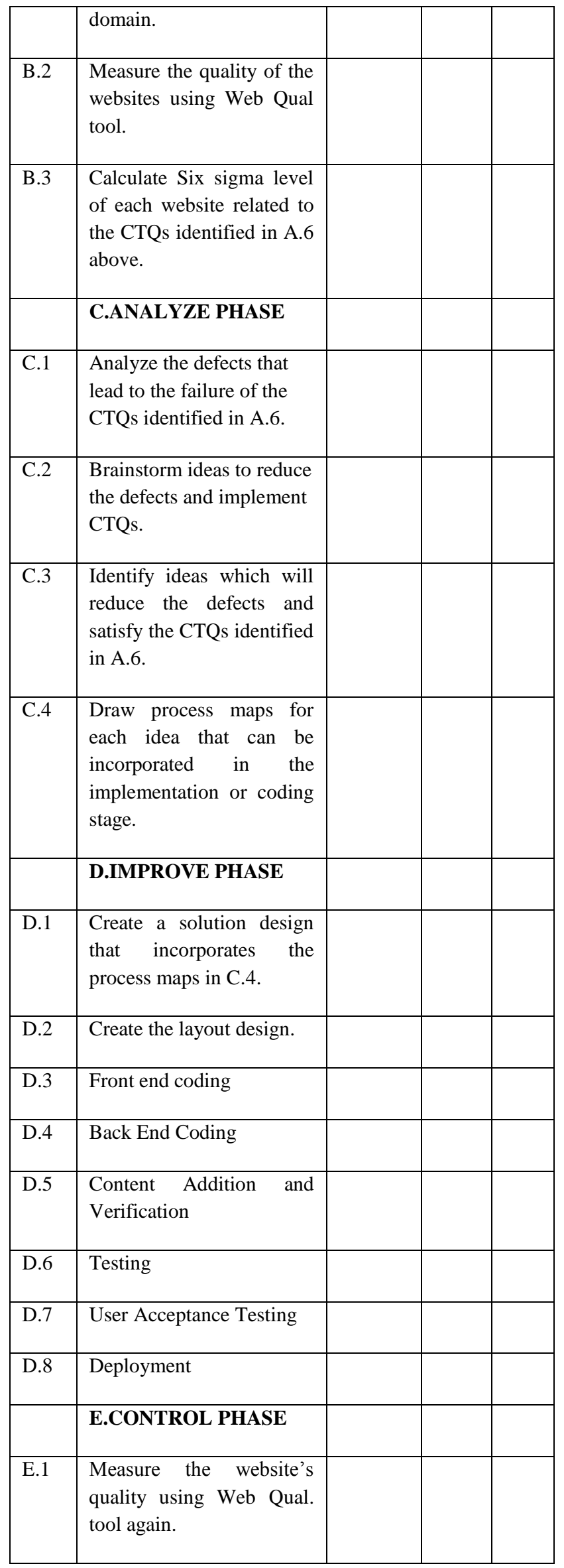

\begin{tabular}{|l|l|l|l|l|}
\hline E.2 & $\begin{array}{l}\text { Check if all the CTQs } \\
\text { have been achieved. }\end{array}$ & & & \\
\hline E.3 & $\begin{array}{l}\text { Continuously monitor } \\
\text { performance. }\end{array}$ & & & \\
\hline E.4 & $\begin{array}{l}\text { Make any corrections if } \\
\text { required. }\end{array}$ & & & \\
\hline
\end{tabular}

\section{B.Measure Phase}

In the measure phase, the list of similar websites are identified and the Six Sigma levels are calculated and customer satisfaction levels are measured using web quality checking tools. The following are the activities in the Measure Phase:

\section{B.1) Activity 1: Listing out competitive websites in the same domain}

The first activity in the MEASURE phase involves identifying existing popular websites with similar goals and objectives and number them according to their popularity ( For example, if we are planning to create a web portal which gives information about cars in the market and their current rates in India , then we can list out the following websites:www.cardekho.com,www.zigwheels.com,www.carw ale.com and www.gaadi.com).

\section{B.2) Activity 2: Measure the Quality of listed} websites.

Measuring website quality is a complex affair [9] because it involves a wide array of tastes, needs and requirements among customers. There are a number of web quality measurement tools available in literature $[4,6]$, but we found that the Web Qual tool by Aladwani and Palvia [2] is comprehensive and more suited to our purpose . Five samples of customers in varying age groups should be created and provided with a questionnaire of the form given in Table 3 below. This is the basic questionnaire with 25 items in four dimensions that can be used to evaluate the quality of any web site. Questions to the customer can be appended, deleted or modified to the above questionnaire depending on the specific attributes, functionality and features of the webs site, domain and purpose whose quality is being evaluated.

Table 3 : WEBDEV Quality Questionnaire

\begin{tabular}{|c|l|c|c|c|c|c|c|c|}
\hline S.No & \multicolumn{1}{|c|}{ Quality Checks } & \multicolumn{3}{|c|}{ Agree } & \multicolumn{2}{c|}{ Disagree } \\
\hline 1. & $\begin{array}{l}\text { Web Site looks secured } \\
\text { for carrying out } \\
\text { Transactions }\end{array}$ & 1 & 2 & 3 & 4 & 5 & 6 & 7 \\
\hline 2 & $\begin{array}{l}\text { Web Site looks easy to } \\
\text { navigate through }\end{array}$ & & & & & & & \\
\hline 3 & $\begin{array}{l}\text { Web site has adequate } \\
\text { search facilities }\end{array}$ & & & & & & \\
\hline 4 & $\begin{array}{l}\text { Website is always up } \\
\text { and available }\end{array}$ & & & & & & & \\
\hline 5 & $\begin{array}{l}\text { Web site has valid links } \\
\text { (hyperlinks) }\end{array}$ & & & & & & & \\
\hline 6 & $\begin{array}{l}\text { Web site is personalized } \\
\text { or customized to meet } \\
\text { one's needs }\end{array}$ & & & & & & & \\
\hline 7 & \begin{tabular}{l} 
Web pages load fast \\
\hline
\end{tabular}
\end{tabular}




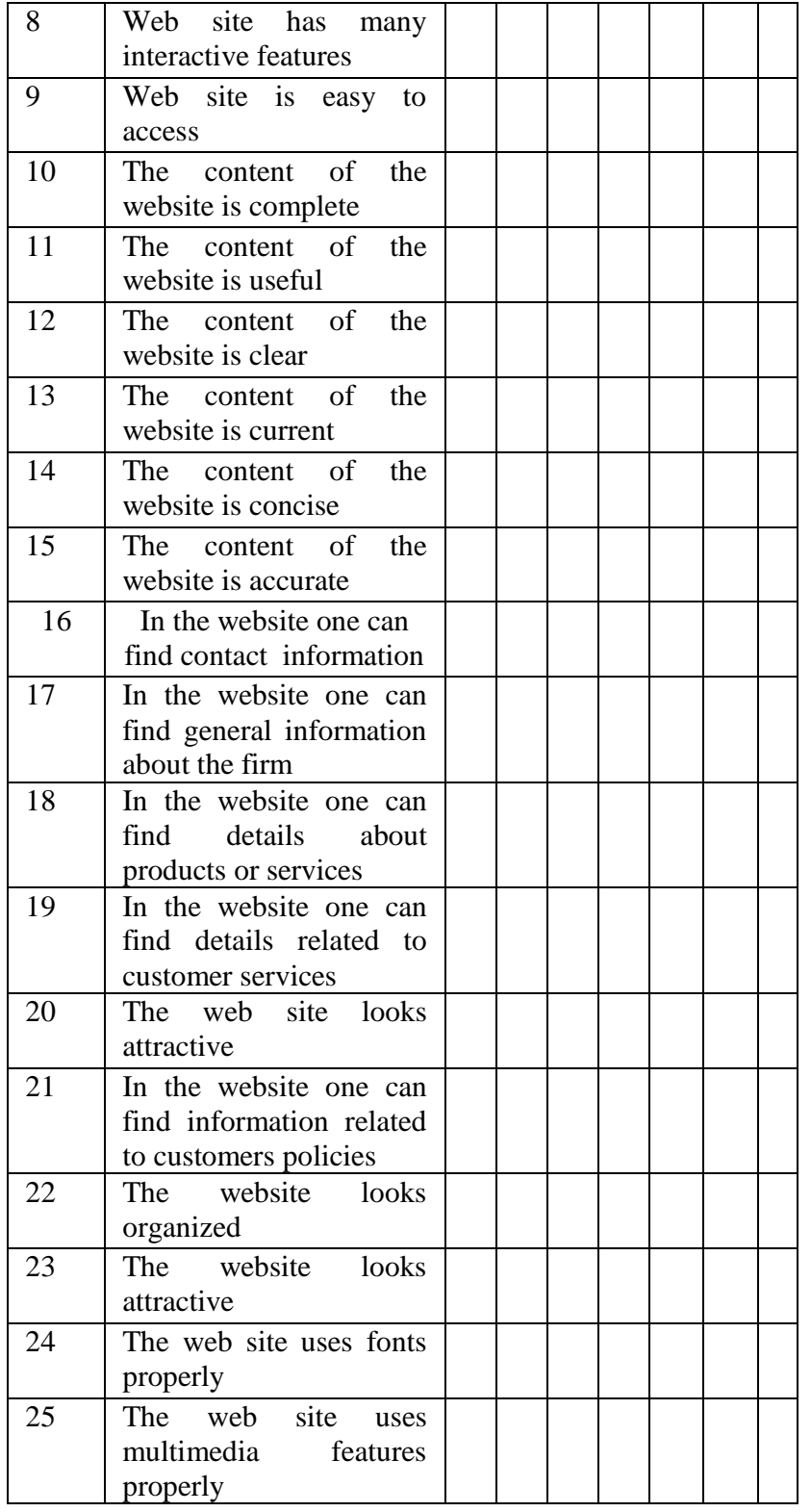

\section{B.3) Activity 3: Calculate the current Six Sigma} level of each website

The Six Sigma level of each website is calculated using the following worksheet given in Table 4 below:

\section{Table 4: WEBDEV Six Sigma Calculator}

\begin{tabular}{|l|l|}
\hline Activity Description & Eg values \\
\hline Count the number of web pages in the website & 75 \\
\hline $\begin{array}{l}\text { Count the number of web pages in the website with } \\
\text { problem }\end{array}$ & 40 \\
\hline Calculate the defects ( Step 2/Step 1) & 0.53 \\
\hline $\begin{array}{l}\text { Count the number of defects per million } \\
\text { opportunities(DPMO) }\end{array}$ & \\
\hline $\begin{array}{l}\text { Convert the DPMO value into Six Sigma Level } \\
\text { using the Table }\end{array}$ & \\
\hline
\end{tabular}

\section{Analyze Phase}

The analyze phase is used to study the results obtained from the above measurements and correlate the defects and the low Sigma levels and to find out the root cause of the defects discovered in the measure phase above. The analyze phase has the following activities:

\section{C.1) Activity 1: Determine the reasons for defects}

The survey forms used for quality measurement are analyzed and the root cause analysis is done. If the 8 customers in a pool of ten strongly disagree that the website has adequate search facilities, it means there is a defect in that area. The reasons for poor search facility has to be analyzed and documented in a Root Cause Analysis table .One reason for a poor search facility can be that the algorithm used is in efficient . In a similar way every quality attribute should be analyzed and entered into the root cause analysis table. The root cause analysis table is shown in Table 4 below:

Table 4 : Root Cause Analysis Table

\begin{tabular}{|l|l|l|l|}
\hline S.No & $\begin{array}{l}\text { Web Portal } \\
\text { Functionality }\end{array}$ & Causes & Frequency \\
\hline 1. & $\begin{array}{l}\text { Inadequate } \\
\text { search Facility }\end{array}$ & $\begin{array}{l}\text { Not linked with } \\
\text { efficient search } \\
\text { engine }\end{array}$ & 1 \\
\hline 2. & $\ldots \ldots \ldots$ & $\ldots \ldots$. & $\ldots \ldots \ldots$ \\
\hline
\end{tabular}

\section{C.2) Activity 2: Brainstorm Ideas that can improve defects}

The team should sit together with the root cause analysis report generated above and try to come up with solutions to reduce the defects by eliminating the root causes. A cost and time ranking document should be prepared in the format as illustrated in Table 5 below:

Table 5: Cost and Time Ranking

\begin{tabular}{|l|l|l|l|}
\hline S.No & Improvement & Cost & Time \\
\hline 1. & Improve the Search engine & Rs.. & -days \\
\hline & & & \\
\hline
\end{tabular}

Every entry in the table should be an improvement that has to be made to correct a defect above and the cost and time required to correct or improve that defect should be highlighted together with the improvement.

\section{C.3) Activity 3: Determine which Improvements are most critical to Customer Requirements.}

List out the improvements that are critical to satisfy the Customer's Quality Requirements identified in documents AD5 and AD6 .Combining and mapping the cost rank table and the Root Cause Analysis table list out the improvements that can be made easily and which will have maximum impact on the customer's requirements .

\begin{tabular}{|l|l|l|l|l|}
\hline S.No & Improvement & Cost & Time & $\begin{array}{l}\text { Impact on } \\
\text { CTQs }\end{array}$ \\
\hline 1. & $\begin{array}{l}\text { Improve the Search } \\
\text { engine }\end{array}$ & Rs.. & days & \\
\hline & & & & \\
\hline
\end{tabular}

\section{C.4) Activity 4: Draw Process Maps}

A process map should be drawn for each listed improvement showing inputs and outputs and logic that can used to implement the improvements. 


\section{Implement Phase}

The Implement phase involves the actual development and deployment of the web portal taking into consideration all the improvements to be made and the defects to be corrected that have been studied and analyzed in the previous phases.

The Define Phase has the following activities:

\section{D.1) Activity 1: Create the layout design}

The layout design of a web portal is the overall template design, number of pages, links between pages etc.It is the first part of the portal that has to be coded.

\section{D.2) Activity 2: Create the Low level design}

The low level design of the portal is the actual development and implementation of each web page in the portal. The process maps that have been developed in activity C. 4 have to be consulted and incorporated into the design.

\section{D.3) Activity 3: Front End Coding}

The coding for the web pages should be completed in this activity. This coding is done using the design developed above as a blue print.

\section{D.4) Activity 4: Back End Coding}

The database of the web portal is created, populated with data and connected to the front end or the web pages.

\section{D.5) Activity 5: Content Verification and Addition}

Finally, it the turn of the content manager to check the data content in the web portal and make additions and modifications if required.

\section{D.6) Activity 6: Verification and Validation:}

At this point a check is made to ensure that all the improvements discussed have been implemented in the web portal using a checklist sheet.

\section{D.7) Activity 7 : Testing}

Finally testing is done to check if the web portal is functioning properly and that all the requirements have been covered.

\section{D.8) Activity 8 : Deployment}

The web portal is finally deployed in the Internet.

\section{E.Control Phase}

The objective of the control phase is to ensure that the improvements made to the web portal are permanent so that the customers are satisfied. This is done by constant and continuous monitoring and the setting of metrics to measure the success or failure of the web portal. The control phase will have the following activities:

\section{E.1) Activity 1: Measure the developed websites} quality.

The web portals quality will be measured using the web Quality questionnaire tool used earlier.

E.2) Activity 2: Measure the sigma level of the website

The Six Sigma level of the web site is measured using the Six Sigma Calculator given in Table 4 above.

\section{E.3) Activity 3 : Check if all the CTQs been achieved}

The SRS, CTQs are revisited and a quality check is carried out to see if all the CTQs are achieved.

\section{E.4) Activity 4: Monitoring Web Portal} Performance

Web portal performance should be continuously monitored. This monitoring should be done once in 3 months continuously.

\section{3 .FUTURE DIRECTIONS}

The quality of web portals has become an important issue today. This paper proposes a design framework called WEBDEV that can be used to design web portals from scratch. The WEBDEV framework is based on the DMAIC methodology that is used in Six Sigma.The next step in this research is to carry out the following steps :

1. Using the WEBDEV framework a web portal will have to be developed and deployed.

2. The quality of the developed web portal will be analyzed using a web quality checking tool.

3. Finally ,a quality comparison will be carried out to check whether the portal developed using the WEBDEV framework meets quality standards of the customers.

\section{ACKNOWLEDGEMENTS}

This research has been sponsored by grants from the Department of Science and Technology (DST), Government of India.

\section{REFERENCES}

[1] AJITH ASHOK SHENVI.2008.Design For Six Sigma: Software Product Quality. In the Proceedings of the First India Software Engineering Conference.97-106.

[2] BASEM.S, EL-HAIK and ADNAN SHAOUT.2010 Software Design For Six Sigma :A Roadmap For Excellence. John Wiley and Sons .Edition 1.

[3] CHRISTINE B.TAYNTOR.2007.Six Sigma Software development. Auerbach Publications .Edition 2.

[4] CHAO-TUN SU,TAI - LING CHIANG and CHE -MIN CHANG.Improving Service Quality by Capitalizing on an Integrated Lean Six Sigma Methodology. International Journal of Six Sigma and Competitive Advantage.Vol2.No1 .1-22.

[5] J.C.WESTLAND , T.H.K.CLARK.1999. Global Electronic Commerce:Theory and Case Studies.MIT Press,Cambridge.

[6] SIVAMUNI KALAIMAGAL and AMGOTH JAGAN 2013.Using Six Sigma in Web Portal Development. accepted at the 2013 IEEE International Conference on Research and Development Prospects on Engineering and Technology (ICRDPET ).Nagapattinam.March $29^{\text {th }}$ and $30^{\text {th. }}$

[7] LAWRENCE I .GOLDMAN and CRYSTAL CAMPBELL.2004.Crystal ball and Design For Six Sigma.In the Proceedings of 2004 Winter Simulation Conference. 1680-1687.

[8] LIU,CHANG and KIRK.P.ARNETT.2000.Exploring the factors associated with Web Site success in the Context of Electronic Commerce, Information and Management.38(1):23-24. 
[9] NEERAJ KUMARI.2011.Applying Six Sigma in Software Companies for Process Improvement .Review of Management. Vol 1 .No 2.21-34.

[10] RICHARD.E.BIEHL.2004.Six Sigma for Software.IEEE Software.Vol 21.No 2.68-70.

[11] STUART.J.BARNES,KENNEY LIU and RICHARD.T.VIDGEN.2001.Evaluating WAP Sites:The WEBQUAL/M Approach. The $9^{\text {th }}$ European Conference on Information Systems.

[12] TIM KRAUSE.2009.A Lean Six Sigma Approach to Web Design. Edition 1.

[13] VOJO BUBEVSKI .2010.An Application of Six Sigma and Simulation in Software Testing Risk Assessment.Third International Conference on Software Testing, Verification and Validation.295-302
[14] VALERIE .A.ZEITHAML, A.PARASURAMAN and ARVIND MALHOTRA.2002. Service Quality Delivery through Websites :A Critical Review of Extant Knowledge.Journal of the Academy of Marketing Science. Vol 30.No 4.358-371.

[15] VICKY NANDA and JEFF ROBINSON.2011.Six Sigma Software Quality Improvement.Tata Mcgraw Hill.edition 1.

[16] YOO,B. and DONTHU .N.2001.Developing a scale to measure perceived quality on an Internet Shopping site (SITEQUAL).Quality Journal of Electronic Commerce Vol(2). No 1.31-46. 